\title{
Numerical simulation of landslide-generated waves using a soil-water coupling smoothed particle hydrodynamics model
}

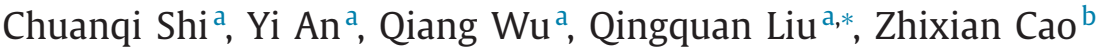 \\ a Key Laboratory for Mechanics in Fluid Solid Coupling Systems, Institute of mechanics, Chinese Academy of Sciences, Beijing, 100190, China \\ ${ }^{\mathrm{b}}$ State Key Laboratory of Water Resources and Hydropower Engineering Science, Wuhan University, Wuhan 430072, China
}

\section{A R T I C L E I N F O}

\section{Article history:}

Received 30 November 2015

Revised 2 April 2016

Accepted 2 April 2016

Available online 7 April 2016

\section{Keywords:}

Landslide induced impulse waves

Smoothed particle hydrodynamics

Soil-water coupling

Elasto-plastic model

Dilatancy angle

\begin{abstract}
A B S T R A C T
We simulate the generation of a landslide-induced impulse wave with a newly-developed soil-water coupling model in the smoothed particle hydrodynamics (SPH) framework. The model includes an elastoplastic constitutive model for soil, a Navier-Stokes equation based model for water, and a bilateral coupling model at the interface. The model is tested with simulated waves induced by a slow and a fast landslide. Good agreement is obtained between simulation results and experimental data. The generated wave and the deformation of the landslide body can both be resolved satisfactorily. All parameters in our model have their physical meaning in soil mechanics and can be obtained from conventional soil mechanics experiments directly. The influence of the dilatancy angle of soil shows that the non-associated flow rule must be selected, and the value of the dilatancy angle should not be chosen arbitrarily, if it is not determined with relative experiments.
\end{abstract}

(c) 2016 Elsevier Ltd. All rights reserved.

\section{Introduction}

Subaerial landslides may generate large impulse waves in lakes or reservoirs, which have a high potential to cause direct damage to the reservoir buildings and residents, and even result in the loss of life. The accurate estimation of the landslide-induced wave hazard is still an open problem because of its complexity. Numerical simulation of this process often faces the following three difficulties, which are essential in this problem: (1) accurate simulation of the large deformation of the slide and the free surface; (2) implementing the bilateral coupling of the slide and the water; and (3) dealing with deformation and movement of the slide and the water in one numerical framework.

Focusing on the last two problems, many numerical studies that ignore the landslide deformation have been developed to simulate landslide-generated waves. In simulations by Heinrich (1992), Monaghan et al. (2003), Ataie-Ashtiani and Shobeyri (2008), Xu (2012), Viroulet et al. (2013) and Serrano-Pacheco et al. (2009) (Table 1), landslides are considered as rigid blocks while the interaction between water and the slide is generally well proposed. Different numerical methods, including smoothed particle hydrodynamics (SPH), coupled Euler-Lagrange, and the finite volume method with a volume of fraction two-phase model, have been used for the simulations and different parameters have also

\footnotetext{
* Corresponding author: Tel.: +861082544202; fax: +860162561284.

E-mail address: qqliu@imech.ac.cn (Q. Liu).
}

been analyzed. The assumption of non-deformable landslide, which is reasonable for rock-dominated landslides, is very helpful in understanding the influence of the essential parameters, such as the still water depth, volume of the slide, and impact velocity.

However, most landslides in nature consist of soil or other deformable granular material, which will have a large deformation because of the interaction with water or boundaries, or both. In this situation, the rigid block model will not be valid. Fritz et al. (2003) found in experiments that the granular slide will deform notably and thus result in a wave different from that of the rigid body. In fact, two different main influences can be summarized by comparing experimental observations. First, the rigid block will either be stopped (Heinrich, 1992) or continue moving along with a smoothly curved track (Walder et al., 2003) when it reaches the bottom of the channel, whereas the granular material landslide will generally deposit in the corner. Second, the granular slide thickness and front angle will continually change during the penetration (Viroulet et al., 2013; Fritz et al., 2001; Fritz et al., 2003) because of the interaction with water, whereas the rigid block will not experience this complex phenomenon. The relative slide thickness will heavily influence wave characteristics, such as the maximum wave amplitude, based on the study of Fritz et al. (2004) on granular slide and Heller and Spinneken (2013) on block slide. Therefore, the deformation of the landslide must be considered in the simulation of landslide-generated waves.

Numerical studies that have considered the effect of slide deformation in landslides impacting water have been carried out 
Table 1

Rigid block model for a landslide.

\begin{tabular}{lllll}
\hline Reference & Simulation method & Impact angle & Landslide shape & Landslide initial position \\
\hline Heinrich (1992) & VOF & $45^{\circ}$ & Triangle & SM \\
Monaghan et al. (2003) & SPH & $10^{\circ}$ & Rectangle & SA \\
Ataie-Ashtiani and Shobeyri (2008) & ISPH & $45^{\circ}, 90^{\circ}$ & Triangle, Rectangle & SM \\
Xu (2012) & CEL & $45^{\circ}$ & Triangle & SM \\
Viroulet et al. (2013) & SPH, FVM & $35^{\circ}$ & Trapezoid & SM, PSM \\
Serrano-Pacheco et al. (2009) & FVM & $30.7^{\circ}$ & Polygon & SA \\
\hline
\end{tabular}

SM: submerged; SA: subaerial; PSM: partially submerged.

Table 2

Non-Newtonian fluid model for a landslide.

\begin{tabular}{|c|c|c|c|c|c|c|}
\hline Reference & Soil model & Simulation method & Impact angle & Landslide initial position & $\begin{array}{l}\mu_{B} \\
(P a \cdot s)\end{array}$ & $\begin{array}{l}\tau_{B} \\
(P a)\end{array}$ \\
\hline Quecedo et al. (2004) & Generalized viscoplastic fluid model & CBG & $45^{\circ}$ & SA & 48 & 1000 \\
\hline Cremonesi et al. (2011) & Changed BM & PFEM & $45^{\circ}$ & SA & 75 & 35 \\
\hline \multirow[t]{2}{*}{ Rzadkiewicz et al. (1997) } & $\mathrm{BM}$ & VOF & $45^{\circ}$ & SM & 0 & 200 \\
\hline & & & & & 0 & 1000 \\
\hline Capone et al. (2010) & Changed BM & $\mathrm{SPH}$ & $45^{\circ}$ & SM & 1 & 1000 \\
\hline \multirow[t]{2}{*}{ Ataie-Ashtiani and Shobeyri (2008) } & BM and Cross model & ISPH & $45^{\circ}$ & SM & 0.1 & 250 \\
\hline & & & & & 0.15 & 750 \\
\hline Mariotti and Heinrich (1999) & $\mathrm{BM}$ & VOF & $45^{\circ}$ & SM & 0 & Update \\
\hline
\end{tabular}

SM: submerged; SA: subaerial; PSM: partially submerged; BM: Bingham model.

recently. Using rheological theory, a non-Newtonian fluid model was used to describe the deformation and movement of landslides by Quecedo et al. (2004), Cremonesi et al. (2011), Rzadkiewicz et al. (1997), Capone et al. (2010), Ataie-Ashtiani and Shobeyri (2008), Mariotti and Heinrich (1999) (Table 2), and Manenti et al. (2015). Simple governing equations and fluid-fluid interaction for the coupling process in this model will reduce the simulated difficulties. The non-Newtonian fluid model can describe some features during the slope deformation; however, it generally overestimates the deformation. In fact, the landslides are mainly composed of granular material and are better described as an elasto-plastic soil model. In this paper, we introduce an elasto-plastic soil model for the slide and the bilateral interaction between soil and water in the simulation to overcome the above shortcomings in the SPH method.

$\mathrm{SPH}$ is a mesh-free method in which continuum or dispersed material is discretized into a set of disordered particles (Monaghan, 2005). These particles will carry field variables, such as mass, density, and stress tensor, and move with the material velocity. No fixed connection between particles or meshes exists, avoiding the inaccuracy from the distorted mesh when dealing with a large deformation and post failure movement of the landslides (Huang et al., 2009). The SPH method has already been used for simulating waves generated by landslides by simplifying the landslide in to a rigid body (Shi et al., 2015; Vacondio et al., 2013) or a nonNewtonian fluid model (Ataie-Ashtiani and Shobeyri, 2008; Capone et al., 2010). Because of its Lagrangian and mesh free characteristics, the SPH method avoids the issue of the simplified treatment of materials' interface in the Euler mesh. As a result, this has the advantage of dealing with the complicated soil-water coupling problem.

In this paper, a novel soil-water coupling model in SPH framework is introduced to simulate the landslide-induced impulse wave problem. The elasto-plastic soil constitutive model is employed to describe the large deformation and post-failure movement of landslides, the traditional weak compressible SPH method is used to simulate the free surface flow of water, and a bilateral coupling of soil and water is designed to consider the interaction between flow and slide. This method can therefore fulfill the three conditions mentioned above to accurately simulate the landslide-induced impulse wave problem. Two experiments (waves generated by a slow and a fast landslide) have been simulated to test the validity of the model and good agreement with experiments is obtained. We present a comparison between our model and a non-Newtonian fluid model to show the model' characteristics in simulating the landslide generated waves. Finally, the influence of the dilatancy angle of soil, which has been ignored in previous studies, is presented and discussed.

\section{Numerical model}

\subsection{Model for water}

The governing equations for fluid flow are the Naiver-Stokes equations, in which the conservation of mass and momentum can be written in SPH Lagrangian form (Liu and Liu, 2004) as:

$\frac{D \rho_{i}}{D_{t}}=\sum_{j=1}^{N} m_{j}\left(v_{i}-v_{j}\right) \cdot \nabla_{i} W_{i j}$

$\frac{D v_{i}^{\alpha}}{D t}=-\sum_{j=1}^{N} m_{j}\left(\frac{P_{i}}{\rho_{i}{ }^{2}}+\frac{P_{j}}{\rho_{j}{ }^{2}}+\Pi_{i j}\right) \cdot \nabla_{i} W_{i j}+g^{\alpha}$

where $\alpha$ is the superscript used to denote the coordinate directions, $N$ represents the total particles in the support domain, and $m$ and $\rho$ are the mass and the density of particles, respectively. $v^{\alpha}$ is the velocity vector, $g^{\alpha}$ is the gravitational acceleration, and $P$ is the pressure. $W$ is the kernel function, which takes the form of the cubic spline function in this study (Liu and Liu, 2004):

$W(r, h)=\alpha_{D} \begin{cases}1-\frac{3}{2} q^{2}+\frac{3}{4} q^{3} & 0 \leq q \leq 1 \\ \frac{1}{4}(2-q)^{3} & 1 \leq q \leq 2 \\ 0 & q \geq 2\end{cases}$

where $q=r / h, r$ is the distance between particles $i$ and $j, h$ is the smoothing length, and $\alpha_{D}$ is $10 / 7 \pi h^{2}$ in two dimensions.

In the SPH simulation, to represent viscosity and to prevent the unphysical penetration of particles, artificial viscosity $\Pi_{i j}$ has been introduced to the momentum equation. Viroulet et al. (2013) tested three viscosity models for landslide induced wave problem, which are the artificial viscosity, the laminar viscosity, and a sub-particle scale (SPS) approach. In their study, good agreement with experiments is observed for all three models, especially the artificial viscosity model. In our model, one of the most widely used types of 
artificial viscosity is introduced as follows (Monaghan, 2005):

$\Pi_{i j}= \begin{cases}\frac{-\alpha \bar{c}_{i j} \mu_{i j}}{\bar{\rho}_{i j}}, & \boldsymbol{v}_{i j} \cdot \boldsymbol{r}_{i j}<0 \\ 0, & \boldsymbol{v}_{i j} \cdot \boldsymbol{r}_{i j} \geq 0\end{cases}$

where $\mu_{i j}=h \mathbf{v}_{i j} \cdot \boldsymbol{r}_{i j} /\left(r_{i j}^{2}+\eta^{2}\right), \eta=0.1 h, \boldsymbol{v}_{i j}=\boldsymbol{v}_{i}-\boldsymbol{v}_{j}, \boldsymbol{r}_{i j}=\boldsymbol{r}_{i}-\boldsymbol{r}_{j}$, $\bar{\rho}_{i j}=\left(\rho_{i}+\rho_{j}\right) / 2, \bar{c}_{i j}=\left(c_{i}+c_{j}\right) / 2$; and $\boldsymbol{v}_{k}, \boldsymbol{r}_{k}, \rho_{k}, c_{k}$ are the velocity, position, density, and speed of sound corresponding to particle $k$ ( $\mathrm{k}$ for $i$ or $j$ ), respectively.

The weakly compressible scheme is employed in this paper for the sake of simplicity, and thus we need the following equation of state (Monaghan, 2005):

$P=B\left[\left(\frac{\rho}{\rho_{0}}\right)^{\chi}-1\right]$

where $\chi=7, B=c_{0}^{2} \rho_{0} / \chi, \rho_{0}$ is a reference density which equals $1000 \mathrm{~kg} / \mathrm{m}^{3}$ for water. The speed of sound $c_{0}$ is at least 10 times the maximum velocity to maintain the density variation within $1 \%$. Here we choose $c_{0}$ equals 20 times the maximum velocity.

The boundary condition is an important issue in SPH models because of the problem of particle deficiency near the solid boundary. Dynamic boundary conditions, a commonly used boundary condition method in SPH, are used in our model (Crespo et al., 2007; Dalrymple and Knio, 2000). In this method, boundary particles follow the same equation as inner particles (Eqs. (1), (2), and (5)), so they can provide support for inner particles. But their positions are not related to the force pairs between boundary particles and inner particles, i.e., they are always fixed on physical boundaries. Here we used a four layers robust staggered dynamic boundary condition which can consider both the boundary movement (translation and rotation) and the boundary shear type (smooth boundary or non-slip boundary).

\subsection{Model for soil}

Large deformation and post-failure movement are essential features of landslides, especially in the landslide-induced wave problem. Characterization of these features is necessary for any numerical methods proposed for this problem. The finite element method (FEM) and the discrete element method (DEM) are classical methods that meet these requirements. However, the mesh of FEM may distort severely and must be remeshed periodically when dealing with the large deformation and post-failure movement. Although the bottom-up DEM does not have this limitation, it relies too much on lower scale parameters, which can be ambiguous (Huang et al., 2009; Bui et al., 2008; Liang and He, 2014).

Conversely, SPH can manage large deformation and post-failure with macroscale parameters without involving mesh issues because of its Lagrangian and adaptive nature (Huang and Dai, 2014). In fact, Shao and Lo (2003), Huang et al. (2009), Huang et al. (2015), and Liang and He (2014) have already applied SPH to simulate the large deformation process using the non-Newtonian fluid model. Bui et al. (2008) first succeeded in simulating elasto-plastic soil behavior using SPH. Wu et al. (2015) also studied the slope failure considering soil-rock interaction using an elasto-plastic soil $\mathrm{SPH}$ model. The governing equations of soil in the framework of SPH consist of mass and momentum conservation equations as follows (Bui et al., 2008):

$\frac{D \rho_{i}}{D t}=\sum_{j=1}^{N} m_{j}\left(v_{i}^{\alpha}-v_{j}^{\alpha}\right) \frac{\partial W_{i j}}{\partial x_{i}^{\alpha}}$

$\frac{D v_{i}^{\alpha}}{D t}=\sum_{j=1}^{N} m_{j}\left(\frac{\sigma_{i}^{\alpha \beta}+\sigma_{j}^{\alpha \beta}}{\rho_{i} \rho_{j}}-\Pi_{i j} \delta^{\alpha \beta}+F_{i j}^{n} R_{i j}^{\alpha \beta}\right) \frac{\partial W_{i j}}{\partial x_{i} \beta}+g^{\alpha}$

where $F_{i j}{ }^{n} R_{i j}{ }^{\alpha \beta}$ is the artificial stress term, helping to remove the tensile instability when soil is stretched; $F_{i j}=W_{\mathrm{ij}} / W(\Delta x, h)$, and the exponent $n$ is set as 2.55 in this paper. $R_{i j}{ }^{\alpha \beta}=R_{i}{ }^{\alpha \beta}+R_{j}{ }^{\alpha \beta}$ where $R_{i}^{\alpha \beta}$ and $R_{j}^{\alpha \beta}$ are the components of the artificial stress tensor for particles $i$ and $j$, respectively. $\sigma^{\alpha \beta}$ is the total stress tensor, while the elasto-plastic soil constitutive model with the Drucker-Prager criterion can be expressed as:

$$
\begin{aligned}
\frac{D \sigma_{i}^{\alpha \beta}}{D t}= & \sigma_{i}^{\alpha \gamma} \dot{\omega}^{\beta \gamma}+\sigma_{i}^{\gamma \beta} \dot{\omega}_{i}^{\alpha \gamma}+2 G \dot{e}_{i}^{\alpha \beta}+K \varepsilon_{i}^{\gamma \gamma} \delta_{i}^{\alpha \beta} \\
& -\dot{\lambda}_{i}\left[3 \alpha_{\psi} K \delta^{\alpha \beta}+\frac{G}{\sqrt{J_{2}}} s_{i}^{\alpha \beta}\right]
\end{aligned}
$$

where $\dot{e}^{\alpha \beta}$ is the deviatoric shear strain rate tensor, $\dot{s}^{\alpha \beta}$ is the deviatoric shear stress rate tensor, $\delta^{\alpha \beta}$ is Kronecker's delta; $K$ is the elastic bulk modulus and $G$ is the shear modulus, which relate to Young's modulus $E$ and Poisson's ratio $v$ through the following equations:

$K=\frac{E}{3(1-2 v)}$ and $G=\frac{E}{2(1+v)}$

$\dot{\lambda}$ is the rate of the plastic multiplier $\lambda$ dependent on the state of stress and load history:

$\dot{\lambda}_{i}= \begin{cases}\frac{3 \alpha_{\phi} K \dot{\varepsilon}_{i}^{\gamma \gamma}+\left(G / \sqrt{J_{2}}\right) s_{i}^{\alpha \beta} \dot{\varepsilon}_{i}^{\alpha \beta}}{9 \alpha_{\phi} \alpha \psi} K+G & f\left(I_{1}, J_{2}\right)=0 \\ 0 & f\left(I_{1}, J_{2}\right)<0\end{cases}$

The elastic strain rate tensor $\dot{\varepsilon}^{\alpha \beta}$ and the spin rate tensor $\dot{\omega}^{\alpha \beta}$ are defined as:

$\dot{\varepsilon}^{\alpha \beta}=\frac{1}{2}\left[\sum_{j=1}^{N} \frac{m_{j}}{\rho_{j}}\left(v_{j}^{\alpha}-v_{i}^{\alpha}\right) \frac{\partial W_{i j}}{\partial x_{i}^{\beta}}+\sum_{j=1}^{N} \frac{m_{j}}{\rho_{j}}\left(v_{j}^{\beta}-v_{i}^{\beta}\right) \frac{\partial W_{i j}}{\partial x_{i}^{\alpha}}\right]$

$\dot{\omega}^{\alpha \beta}=\frac{1}{2}\left[\sum_{j=1}^{N} \frac{m_{j}}{\rho_{j}}\left(v_{j}^{\alpha}-v_{i}^{\alpha}\right) \frac{\partial W_{i j}}{\partial x_{i}{ }^{\beta}}-\sum_{j=1}^{N} \frac{m_{j}}{\rho_{j}}\left(v_{j}^{\beta}-v_{i}^{\beta}\right) \frac{\partial W_{i j}}{\partial x_{i}^{\alpha}}\right]$

where $f\left(I_{1}, J_{2}\right)$ is the yield function, $I_{1}$ and $J_{2}$ are the first and second invariants of the stress tensor, respectively; $\alpha_{\varphi}$ and $k_{c}$ are Drucker-Prager's constants, which are related to the MohrCoulomb material constants $c$ (cohesion) and $\varphi$ (internal friction), and $\alpha_{\psi}$ is a dilatancy factor that can be related to the dilatancy angle. For more details, please refer to Bui et al. (2008).

\subsection{Soil-water coupling model}

In the landslide-induced impulse wave problem, the interaction between slide and fluid, i.e., soil and water, is a local surface force located at the soil-water interface. Moreover, this surface force may contribute, or even dominate, the soil deformation of the slide, which in turn influences the flow characteristics of water. Shakibaeinia and Jin (2011) employed a fluid-fluid interface coupling technique in the scope of $\mathrm{N}-\mathrm{S}$ equation with different material parameters instead of elasto-plastic model which many engineers on soil mechanics would prefer for landslide problems. Unilateral coupling methods, such as sediment flushing where a Mohr-Coulomb erosion criterion is used to decide the interfacial soil particle to be at rest or eroded by Manenti et al. (2012), would not work in the simulation of impulse waves. Furthermore, the approach of introducing a seepage force by Huang et al. (2013) will not be suitable for the rapid change of interface and the strong interaction force, because the seepage parameter is difficult to determine. In fact, landslides will rush into the water with a relative high velocity resulting in a short time of interaction only located at the interface. Therefore, the interface between the slide and water 


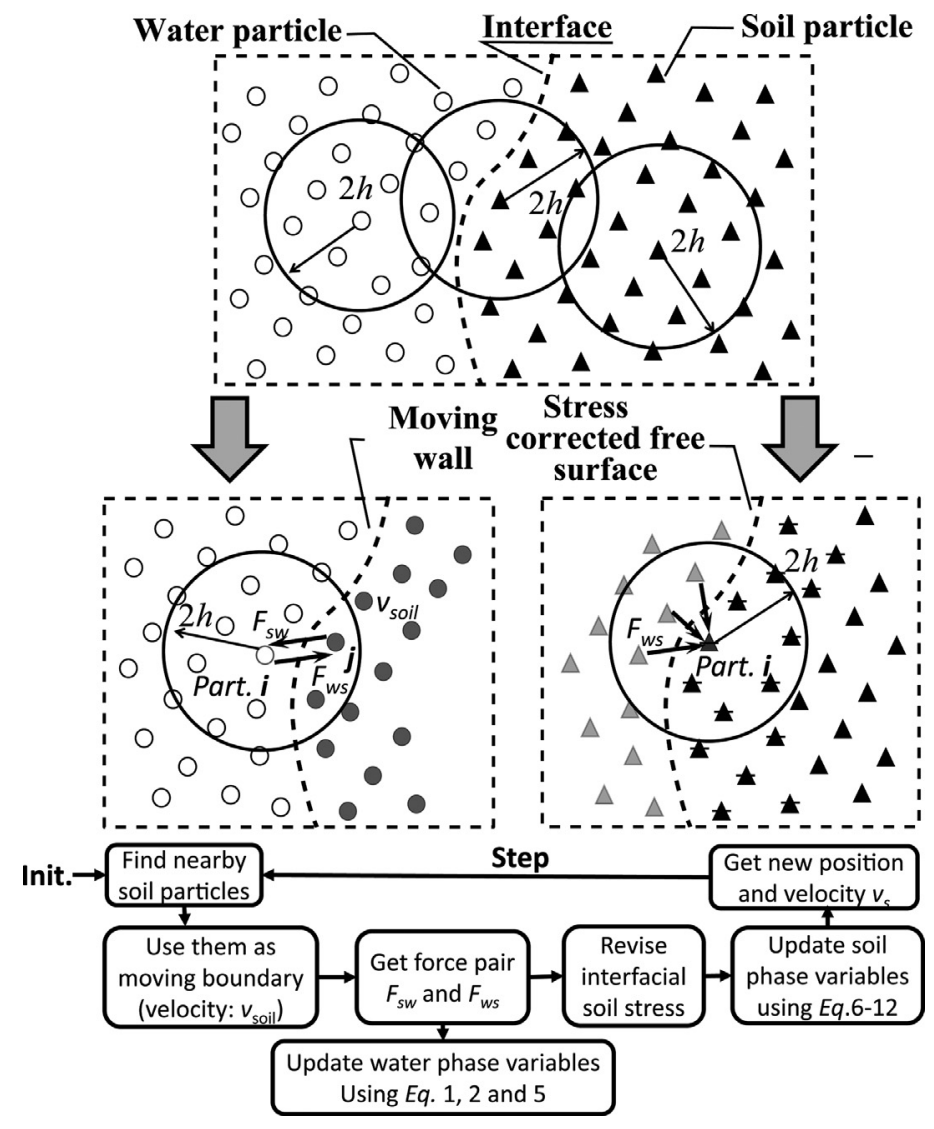

Fig. 1. Soil and water particles near the interface.

can basically be considered as a moving and deforming boundary while the stress and the deformation should be consistent at the interface (Shao, 2012).

Assuming there is a soft deforming shell separating the soil and water, the dynamic boundary condition (moving wall) could be exerted on the shell for the water phase, and the stress corrected free surface boundary condition could be applied for the soil phase. As long as the stress and the displacement are consistent on the shell, the coupling could be achieved. In practice, the water phase (blank circles in Fig. 1) is solved firstly. All we need at the interface is position and velocity of the boundary (grey circles in Fig. 1) which could be reasonably represented by interfacial soil particles. Therefore, extra information for supporting water calculation is stored in the interfacial soil particles (black triangle with bar in Fig. 1), especially the force pairs $\left(f_{\mathrm{sw}}\right.$ and $\left.f_{\mathrm{ws}}\right)$ between water particles and boundary particles. Using these force pairs, the stress on the interface for soil particles (black triangle with bar in Fig. 1) can be corrected. Then the soil constitutive equation is solved with the external stress on the interface in Eq. 7. Once the position and velocity of the soil particles (black triangles in Fig. 1) are updated, the boundary conditions (grey circles in Fig. 1) for water calculation are ready and another cycle could start. In this way, the coupling between water and soil is achieved and limited extra computational cost is spent.

Theoretically, a compromise of the two force pairs from each phase should be achieved with dual timestep method which has an iteration in each timestep comparing with the proposed model. While in this model, the time evolution is explicit which means the calculated interface force is not strictly the accurate solution in each timestep. However, we found that this simple coupling approach is acceptable for the situation of landslide induced impulse wave, because the displacement of the interface is basically deter- mined by soil deformation, and it is relative small in each timestep, so the pressure distribution in fluid phase do not change very much in each timestep, i.e., even if an iteration exists, it would be easy to converge. However, that means we need a small timestep because of the explicit nature of the coupling method. The second disadvantage of this model is that the boundary might fail to stop different phases penetrating the interface. In this study, we simply use the small timestep to solve this problem.

\subsection{Numerical configuration}

Time-step control is dependent on the CFL condition, the forcing terms and the viscous diffusion terms. A variable time step $\Delta t$ is calculated as (Monaghan and Kos, 1999):

$\Delta t=C F L \cdot \min \left(\Delta t_{f}, \Delta t_{c v}\right)$

with

$\Delta t_{f}=\min _{i}\left(\sqrt{\frac{h}{\left|f_{i}\right|}}\right) \Delta t_{c v}=\min _{i} \frac{h}{c_{s}+\max _{j}\left|\frac{h \mathbf{v}_{i j} \mathbf{r}_{i j}}{\mathbf{r}_{i j}^{2}}\right|}$

Here $\Delta t_{f}$ is based on the magnitude of the force per unit of mass for particle $i\left|f_{i}\right|$, and $\Delta t_{c v}$ combines the Courant and the viscous time-step controls. CFL is the Courant number and $\mathrm{CFL}=0.2$ is used in this work.

Eqs. (1), (2), (6), (7), and (8) are integrated using the Verlet algorithm (Verlet, 1967) in time evolvement. The artificial viscosity $\Pi_{i j}$ is used in our model as shown in Section 2.1. The values of parameter $\alpha$ in it are empirically chosen according to similar simulations with experimental validations by Monaghan et al. (2003), Viroulet et al. (2013), and Bui et al. (2008). In this paper, we selected $\alpha=0.1$ for water and $\alpha=0.01$ for soil in the case of a slow 


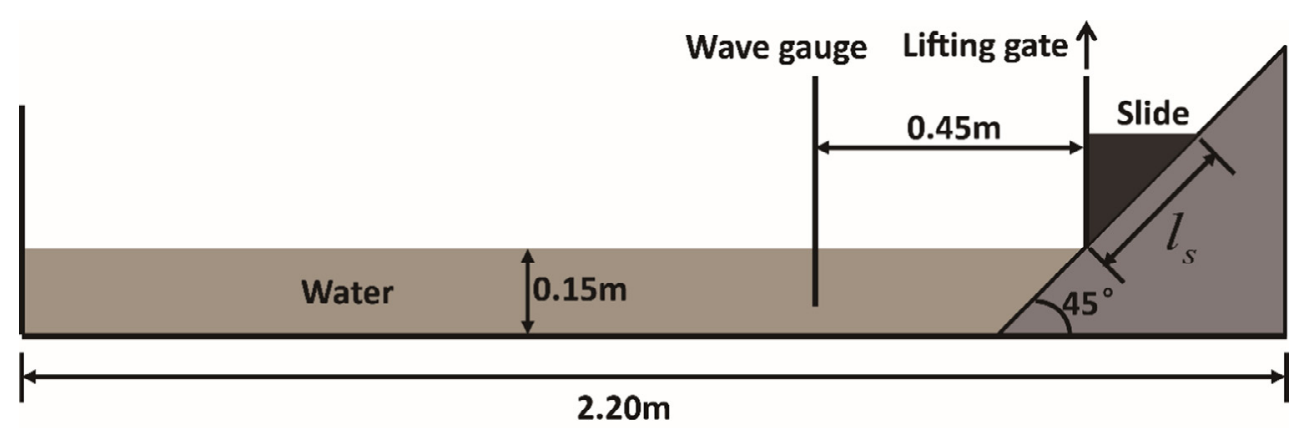

Fig. 2. Sketch of the experimental setup for the case of a slow landslide.

Table 3

Values of Soil Parameters for Simulations.

\begin{tabular}{llllllll}
\hline Cases & $\rho_{g}\left(k g \cdot m^{-3}\right)$ & $n(\%)$ & $c(k P a)$ & $\varphi(\circ)$ & $\psi(\circ)$ & $E(M P a)$ & $v$ \\
\hline Slow landslide & 2500 & 40 & 0 & 23.3 & 0 & 20 & 0.3 \\
Fast landslide & 2640 & 39 & 0 & 43 & 14 & 20 & 0.3 \\
\hline
\end{tabular}

landslide, and $\alpha=0.03$ for water and $\alpha=0.1$ for soil for a fast landslide.

\section{Test cases and results}

Fritz et al. (2003) observed in experiments that the slide impact and wave generation flow fields could be classified into unseparated and separated flow. At high impact velocities, flow separation occurred on the slide shoulder resulting in a hydrodynamic impact crater. Conversely, at low impact velocities, water would climb along the slide shoulder and up to the slope ramp. As a result, no flow separation was observed. In this paper, we chose these two types of characteristic experimental examples and simulate the entire process of a landslide-generated wave.

\subsection{Slow landslide}

In this section, the present model is used to simulate the waves generated by granular material sliding down a slope and collapsing into a water tank, which is a laboratory experiment performed by Viroulet et al. (2013, 2014) (Fig. 2). In this experiment, the slide began to move after the lifting gate was opened and impacted into the water at a low velocity, generating waves propagating along the tank. Typically, $F r \sim 0.2-0.8$ in the experiments. Two situations were simulated: the slide masses $m_{s}=2 \mathrm{~kg}\left(l_{s}=0.165 \mathrm{~m}\right)$ and $m_{s}=3 \mathrm{~kg}\left(l_{s}=0.203 \mathrm{~m}\right)$. The slide is composed of glass beads with a grain density, $\rho_{g}=2500 \mathrm{~kg} . \mathrm{m}^{-3}$, and a bulk slide porosity, $n=40 \%$. Water is sufficiently mixed into the grain as the landslide slowly slides into the water, so the medium bulk density, $\rho_{s}=(1-n) \rho_{g}+n \rho_{w}=1900 \mathrm{~kg} \mathrm{~m}^{-3}$, is used for the computations. This might slightly influence the slope, but will do well in representing the characteristics of the water-soil coupling. In Table 3 , the values of soil parameters $\rho_{g}, n, c, \varphi$, are from laboratory measurement by Viroulet et al. (2014). And these values will be used in the simulation directly. Unfortunately other parameters including $\psi, E, v$ which could be obtained from soil mechanics experiments, were not measured in their experiments. So the values of $E$, $v$ are given by estimation from statistics of soil mechanics experiments considering the material and size of the grains, and values of $\psi$ is considered as a parameter here which will be discussed in Section 4.2.

A comparison between the experimental and simulated wave profiles at the wave gauge is shown in Fig. 3. We see good agreement between experimental data and computational results, especially for the maximum crest amplitude of the leading wave, which

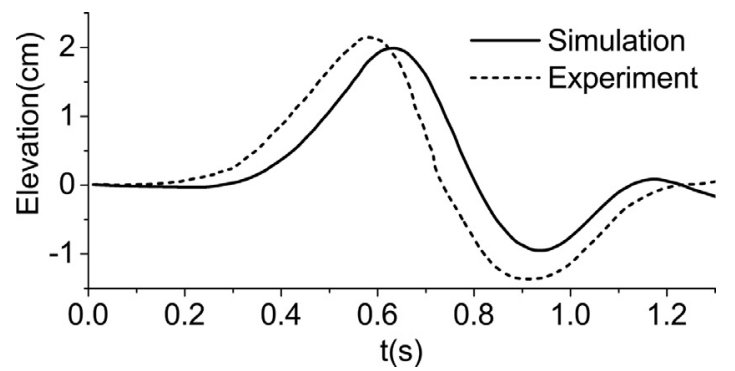

Fig. 3. Elevation of the free surface at wave gauge $x=0.45 \mathrm{~m}$ while $l_{s}=0.165 \mathrm{~m}$.

shows the ability of the model to simulate the impulse waves by a slow landslide. A delay about $0.05 \mathrm{~s}$ can also be observed for simulated free surface elevation in Fig. 3 comparing with the experiment. This delay may result from the treatment of bulk density $\rho_{s}$, which might be overestimated before the main body of the landslide runs into the water. This overestimated bulk density in the simulation may generate a faster deformation, causing the main body of the landslide rushes into the water earlier than that in the experiment.

The flow field and soil configuration of the experiment and simulation are presented at different times in Fig. 4. The qualitative agreement of the soil and water configurations is satisfactory. Moreover, some characteristic details of the flow field show good agreement between experimental observations and simulated results. Fig. 4a shows that water in front of the landslide is elevated when the landslide has just begun sliding into the water. The front part of the elevated water has a greater velocity. The entire flow field showed that the velocity vector was directed from the head of the landslide to the surrounding water, and water closer to the head of the landslide always had a higher velocity. Fig. 4b shows that the velocity magnitude of the water crest had an asymmetric distribution, where the front part was larger. This means that the impulse wave had not yet achieved a steady shape. The water behind the water crest would move downward and the water in front of the landslide would move upward. These two sections of water would meet, causing a stagnant zone, which would travel some distance along the tank as shown in Fig. 4c. In Figs. 4b and c, a different thickness of the landslide leading edge can also been seen between the experiment and simulation. That is because the velocity of water phase is large and the confining pressure of soil grain is weak at the leading edge of the landslide, which leads to 
a

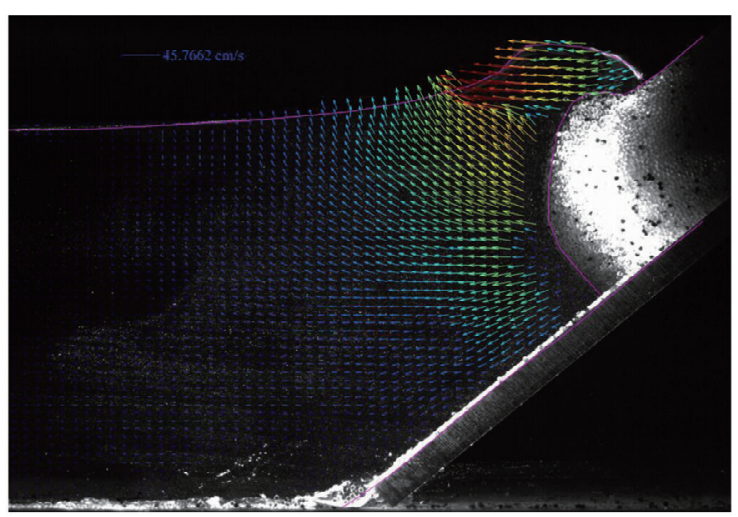

b

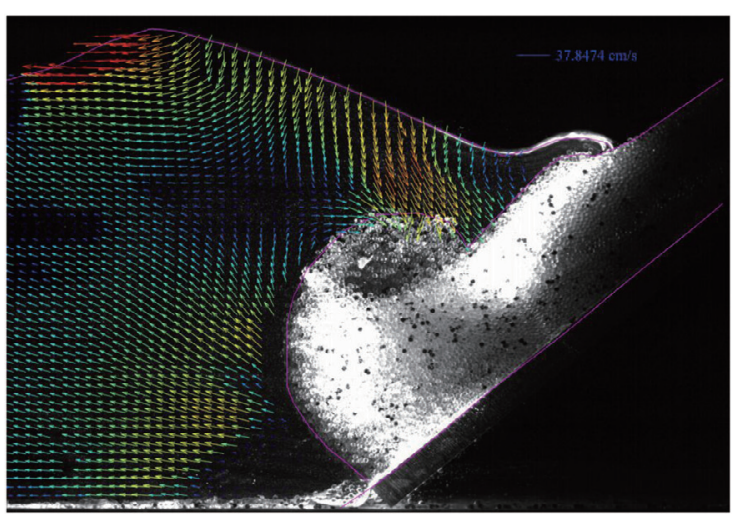

C

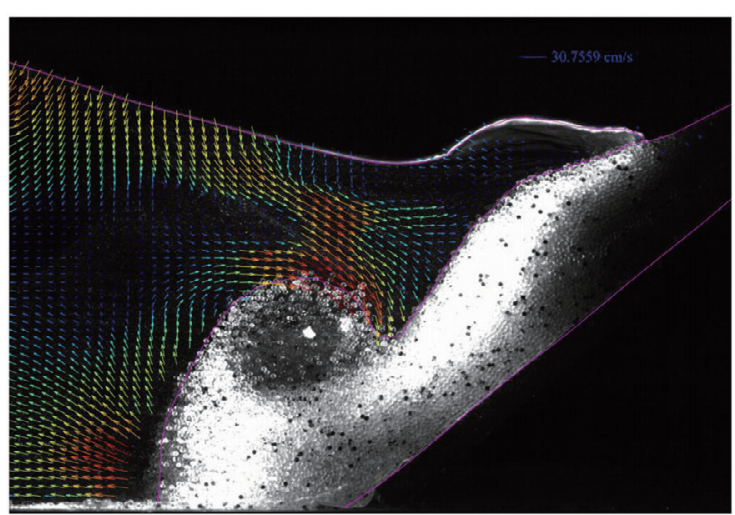

d

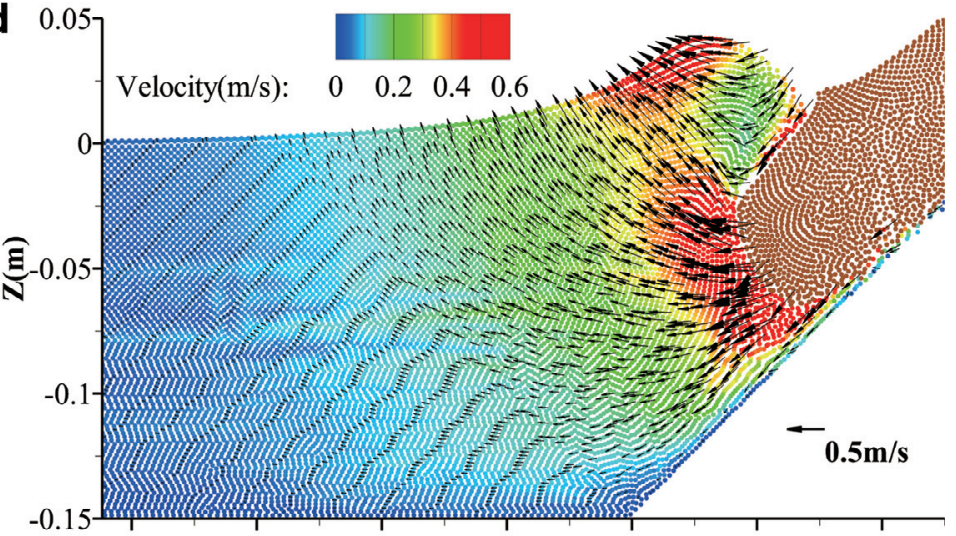

e

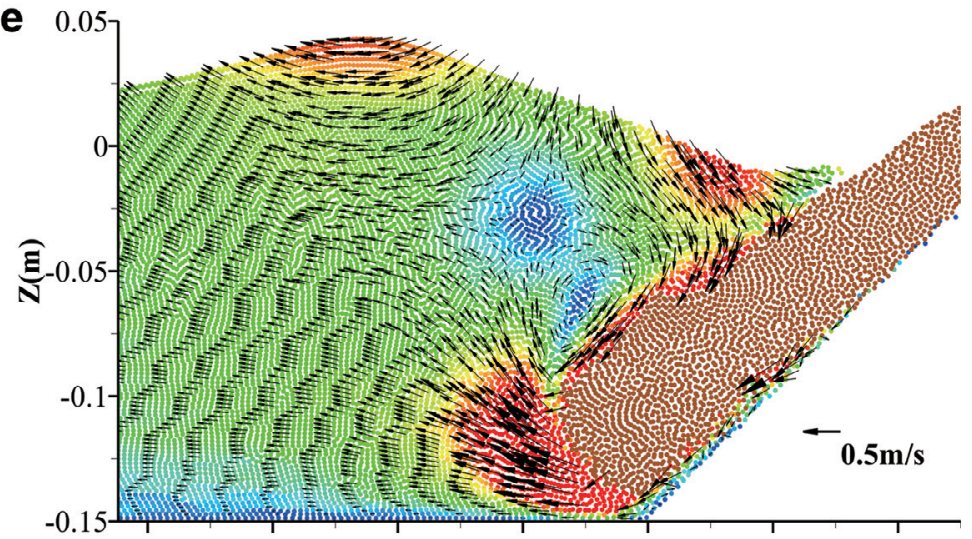

f 0.05

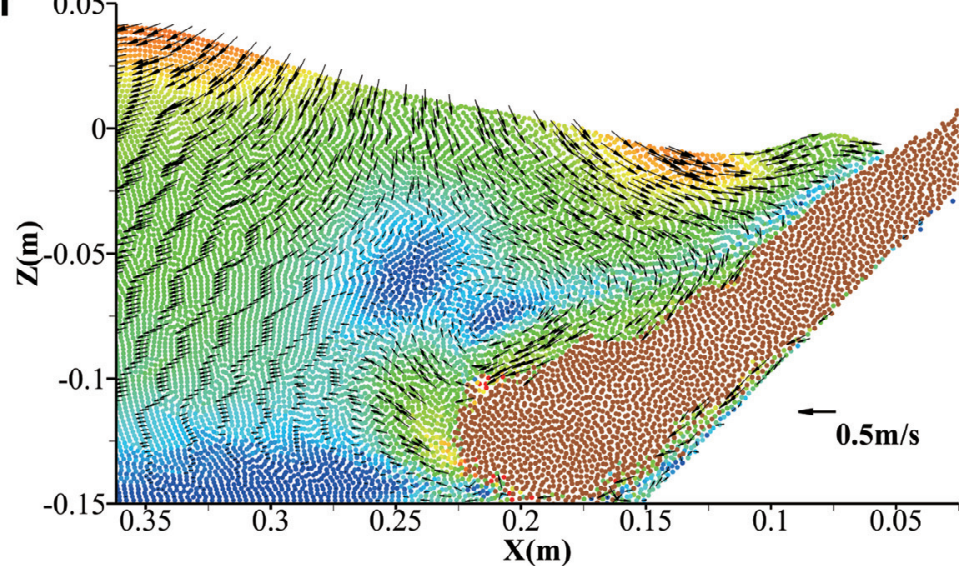

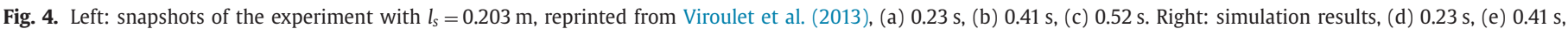
(f) $0.52 \mathrm{~s}$. It should be noticed that the figures at right side have larger zone than the left ones.

rolling up of the grains in the experiments, while the proposed model cannot reproduce this mechanism properly which results a smaller thickness. However, dense fluid as these rolling up grains are, they will have little influence on neither internal stress of soil nor the leading wave.

\subsection{Fast landslide}

A fast landslide triggered by an earthquake in 1958 in Lituya Bay of Alaska, USA caused a megatsunami. The process, including the generation, propagation, and run-up of the impulse waves, was reproduced at a 1:675 scale in a two-dimensional physical laboratory model by Fritz et al. (2001, 2009). The experimental data were in good agreement with the observations of the real event. In the experiment, the landslide began to move with a release velocity generated by a pneumatic landslide generator. The initial situation is shown in Fig. 5.

Because of the abundant detailed experimental data, this experiment by Fritz et al. has been chosen to test the different calculation models used in many previous studies (Mader and Gittings, 2002; Basu et al., 2010; Weiss et al., 2009). Quecedo et al. (2004) used a Level Set technique to track the interfaces between the solid and air, the solid and the fluid, and the fluid and air. A generalized viscoplastic fluid model was used to describe the landslide. Schwaiger and Higman (2007) applied a Newtonian fluid model in the SPH method for the landslide.

The landslide entered the water with a high velocity with $F r=3.18$, causing a mix of water and landslide that was not easy to distinguish in the experiment. We therefore averaged the density of the grain and air in the landslide and obtain $\rho_{s}=(1-n) \rho_{g}=$ 


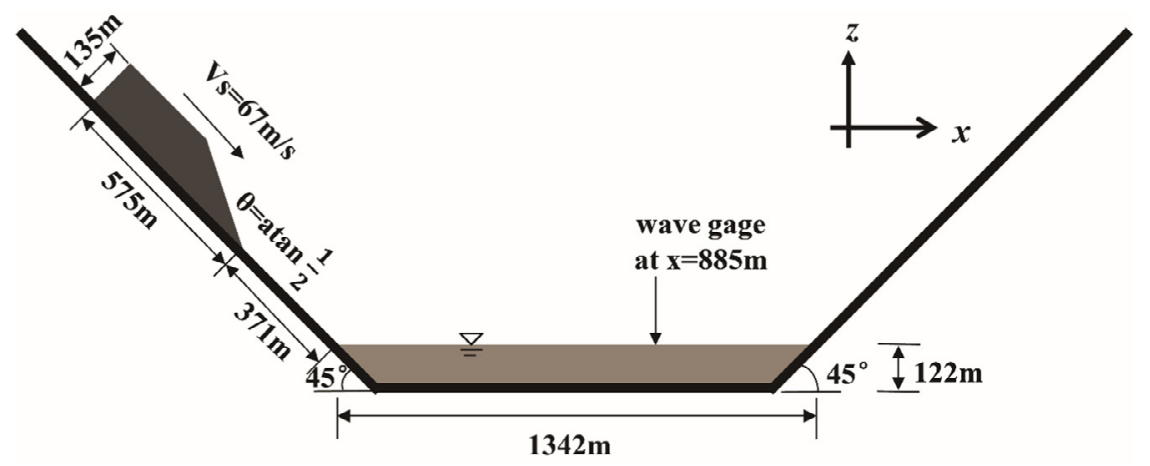

Fig. 5. Sketch of the experimental setup for the case of a fast landslide.

a
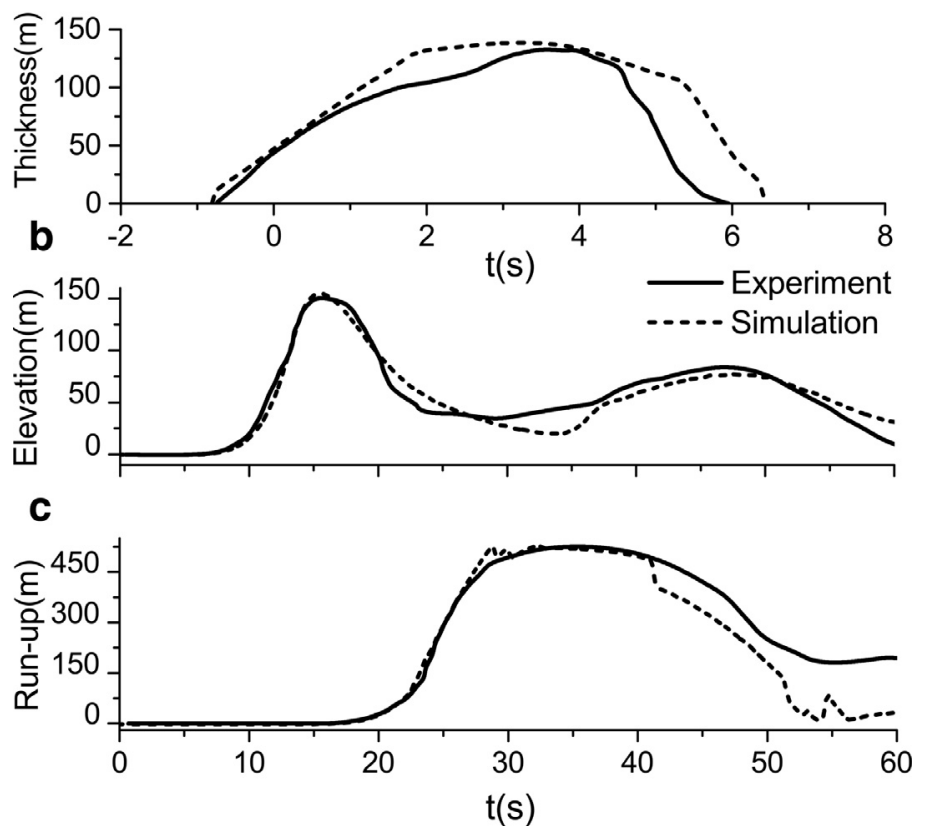

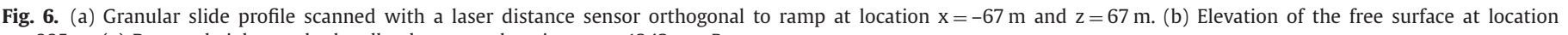
$\mathrm{x}=885 \mathrm{~m}$. (c) Run-up height on the headland ramp at locations $\mathrm{x}=1342 \mathrm{~m}+$ Run-up

$1620 \mathrm{~kg} \mathrm{~m}^{-3}$ for the simulation. The evolution of landslide profile before impact, the water elevation at the wave gauge and the runup height are shown in Fig. 6. The satisfactory agreement between experimental data and the simulated results demonstrates that the proposed model can be applied to impulse waves generated by a fast landslide. In the experiment, a pneumatic landslide generator models the transition from block slide motion to granular flow. This is not fully reproduced in the simulation which might results some differences about slide profile (Fig. 6a). Still, agreement of maximum thickness and slope of head will help to guarantee the accuracy of impacting process.

The configuration of the landslide and water is shown in Fig. 7. Time equals to zero when the impact occurs. The entire process was divided into two main stages by Fritz et al. First: slide impact and penetration (Fig. 7a), flow separation and cavity formation (Fig. 7b, c), while the slide penetration velocity exceeds the wave propagation velocity. Second: cavity collapse (Fig. 7d), slide run-out along channel bottom, and slide detrainment and deposition (Fig. 7e, f) as the wave overtakes the landslide and propagates out of the impact area. During the main period of generation, the three phases (soil, water, and air) were clearly separated along distinct borders (Fig. 7a-d). Phase mixing had little effect on the leading wave because the main wave had propagated out of the impact area before air detrainment occurred (Fig. 7e and f). The comparison of the detailed stages between experimental observations and calculated results again shows the accuracy of the model. We could also extract information of soil deformation in the simulation results which is hard to obtain in the experiments. The accumulated plastics strain (ADPS) which could be considered as indication of the shear induced plastics band are shown in simulated results. It is clear that the plastics zones are located at two interfaces: (1) interface between the slide and the bottom due to the shear of the wall, which also leads many inner plastics zones, (2) interface between the slide head and the water. As the time goes, the direction of the inner plastics zone changes which is a conjunct result of the slide slowdown and the slide getting thinner.

\section{Discussion}

\subsection{Comparison with a non-Newtonian fluid model}

As mentioned above, to simulate the large deformation of landslide-generated impulse waves, most numerical models describe the landslide as a non-Newtonian fluid. There are many rheological models to simulate these fluids. The Bingham model is the simplest and the best known, and can be written as 

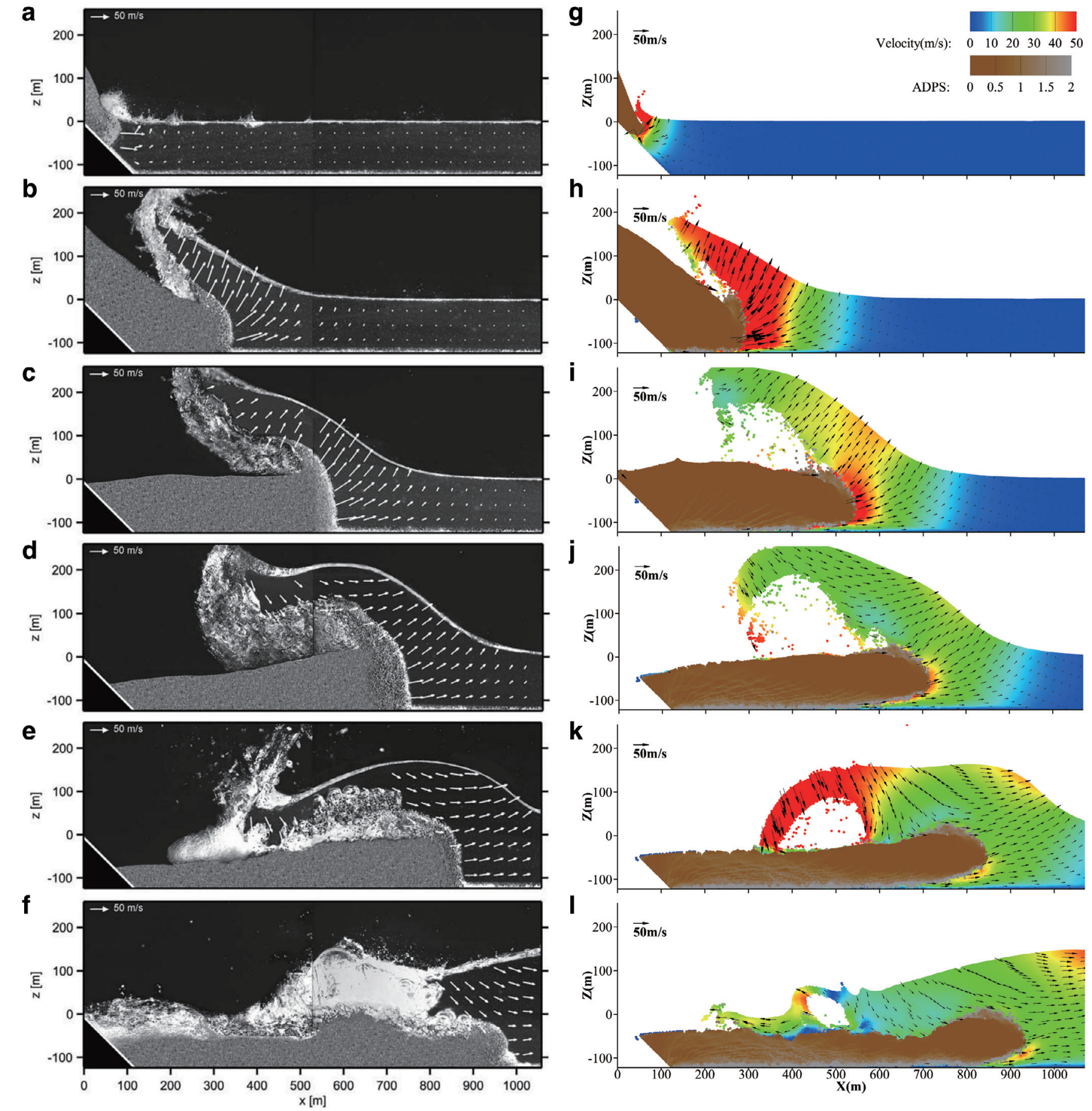

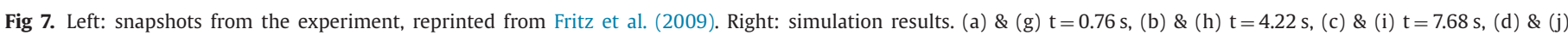
$\mathrm{t}=11.14 \mathrm{~s}$, (e) \& (k) $\mathrm{t}=14.6 \mathrm{~s}$, (f) \& (l) $\mathrm{t}=18.06 \mathrm{~s}$ after impact.

(Shao and Lo, 2003):

$\tau= \begin{cases}2 \mu_{B} e(\mathbf{v})+\tau_{B} \frac{e(\mathbf{v})}{|e(\mathbf{v})|} & \text { if }|\tau|>\tau_{B} \\ 0 & \text { if }|\tau| \leq \tau_{B}\end{cases}$

where $e(\mathbf{v})=\frac{1}{2}\left(\nabla \mathbf{v}+\nabla \mathbf{v}^{T}\right), \mu_{B}$ and $\tau_{B}$ are shear rate tensor, viscosity, and Bingham yield stress, respectively.

Although many non-Newtonian models could reproduce the deformation of landslides very well (Ataie-Ashtiani and Shobeyri, 2008; Rzadkiewicz et al., 1997; Capone et al., 2010; Mariotti and Heinrich, 1999), two significant characteristics of our coupling model can be seen compared with non-Newtonian fluid models. The first one is about the method for choosing the values of pa- rameters. In many cases of non-Newtonian fluid models, values of the parameters need to be determined indirectly related to soil parameters. These values may be quite variable in different cases or even in the same case but based on different models. Experiments of impulse waves generated by a submarine landslide conducted in 1994 with the collaboration of the CEMAGREF Institute have been used to test non-Newtonian fluid models by Rzadkiewicz et al., Mariotti et al., Ataie-Ashtiani et al., and Capone et al. Although some different improvements have been carried out in the models based on Equ. 14, these models use equations similar to Eq. 14. The values of the parameters in these models are clearly different from each other, as shown in Table 2. However, 
a

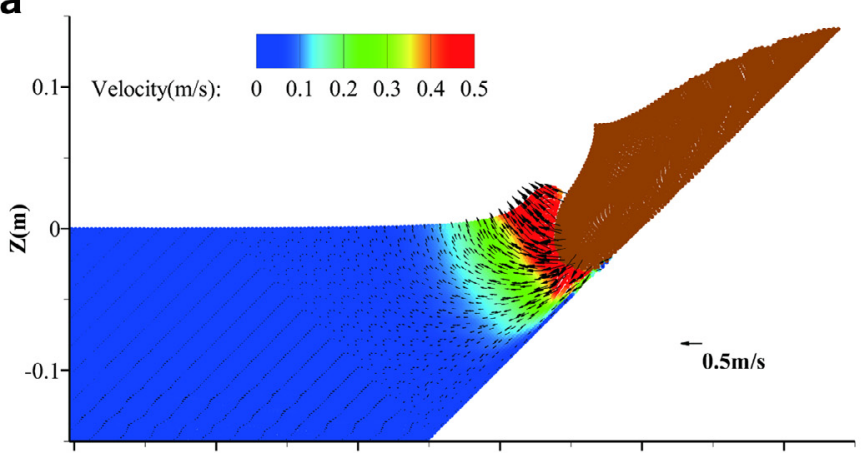

b

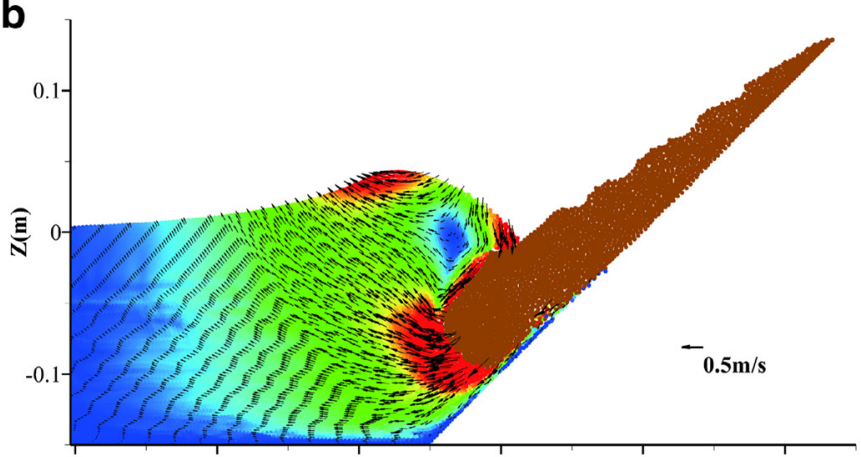

C

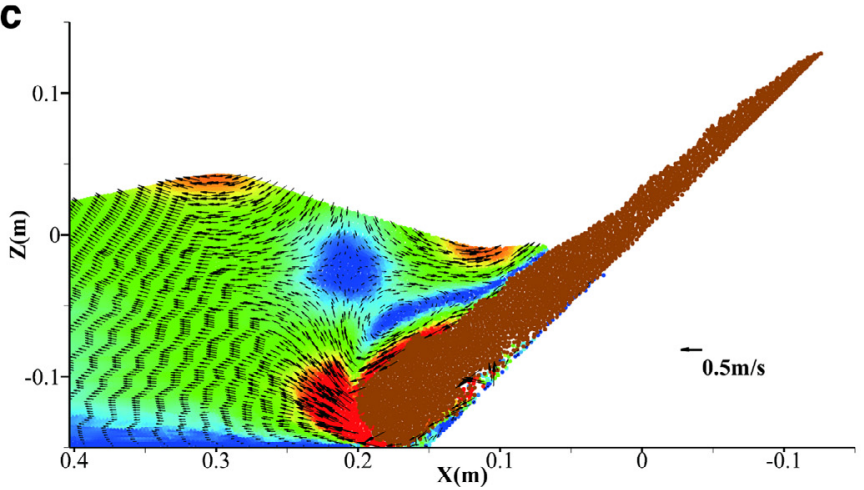

d

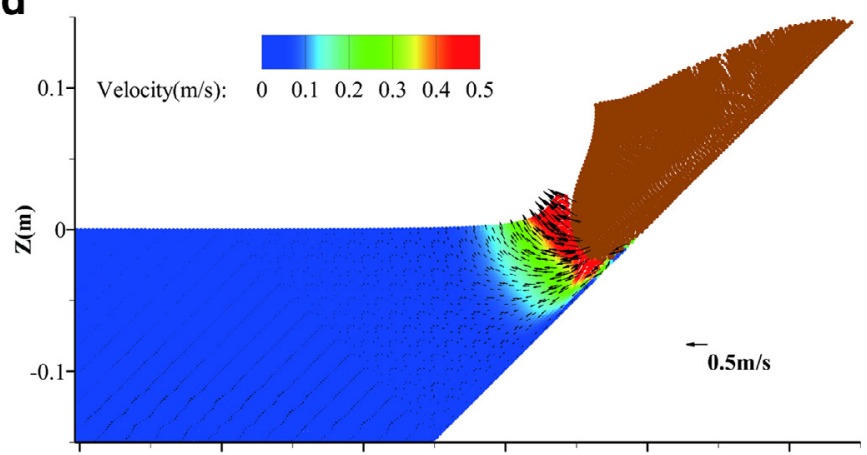

e

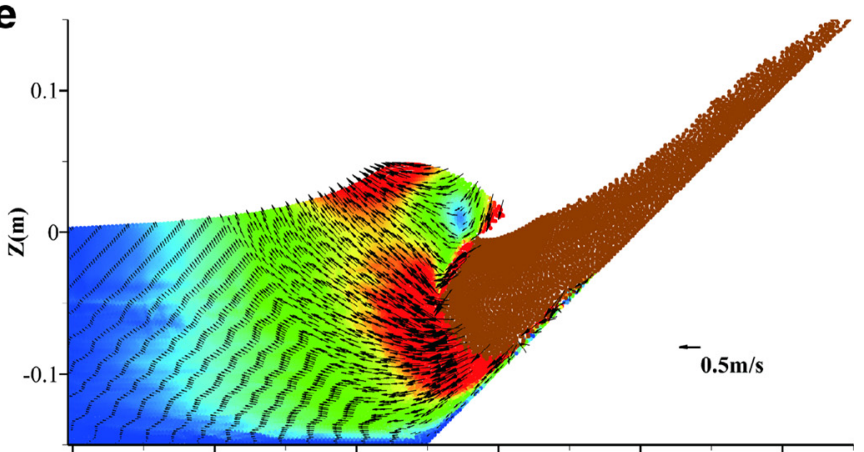

f

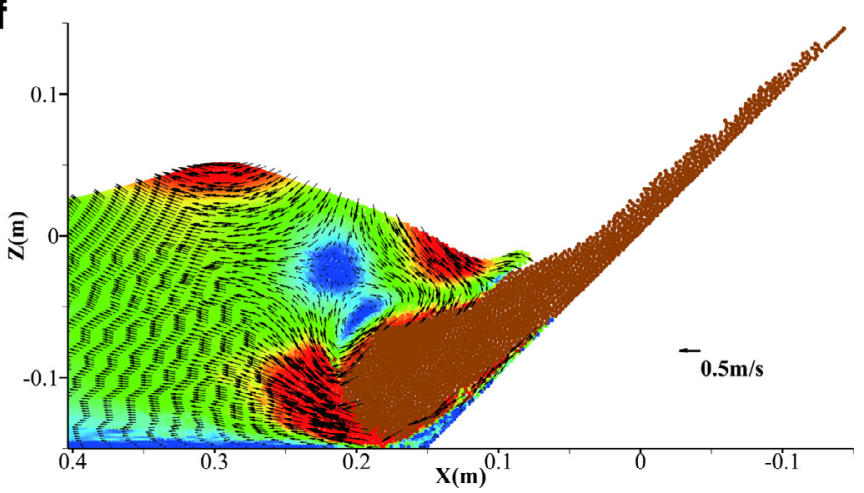

Fig. 8. Left: $\psi=0$ at times of (a) $t=0.15 \mathrm{~s}$, (b) $\mathrm{t}=0.3 \mathrm{~s}$, and (c) $\mathrm{t}=0.45 \mathrm{~s}$. Right: $\psi=12^{\circ}$ at times of (d) $t=0.15 \mathrm{~s},(\mathrm{e}) \mathrm{t}=0.3 \mathrm{~s}$, and (f) $\mathrm{t}=0.45 \mathrm{~s}$.

for the proposed coupling model, it will be more direct and clear when obtaining the values of parameters because of the adoption of the elasto-plastic soil constitutive model. All parameters of the Drucker-Prager model in Equs. 8 and 10 , such as $K, G, c, \varphi$, and $\psi$, have their physical meaning in soil mechanics and can be obtained from normal soil mechanics experiments directly. This convenient method for choosing the parameter values will improve the application of our model in the simulation of real geological situations.

The second characteristic is that structure of the landslide body is better represented in the case of a fast landslide in our model than in the non-Newtonian fluid models as mentioned above. For a saturated submerged landslide, like the experiment of submarine landslide mentioned above, a good agreement can be seen between the simulation results of non-Newtonian fluid models and experiments data (Ataie-Ashtiani and Shobeyri, 2008; Rzadkiewicz et al., 1997; Capone et al., 2010; Mariotti and Heinrich, 1999). But for a fast subaerial landslide, like the experiment of Fritz et al, the landslide may behave too softly with the non-Newtonian fluid models compared with the real situations (Quecedo et al., 2004; Cremonesi et al., 2011). Conversely, the elasto-plastic soil model used in our model can successfully simulate the structure of the landslide body during the entire process of the soil rushing into the water (Fig. 7).

\subsection{Influence of the dilatancy angle}

Change in volume due to grain redistribution will significantly influence the shear capacity of the soil. The dilatancy angle $\psi$ is used to characterize this change of volume in geotechnical engineering: $\psi>0$ when the volume becomes larger and $\psi=0$ when the volume is unchanged. However, the influence of the dilatancy angle has not been sufficiently considered in the existing experiments, which creates a free parameter to the proposed model and the influence of this parameter will therefore be discussed. Two simplified assumptions that have most often been used to solve geotechnical problems are: (1) $\psi=0$ in the non-associated flow rule, which will ignore the influence of the change of volume, for example Bui et al. (Liu and Liu, 2004); and (2) $\psi=\phi$ in the associated flow rule, which will enlarge the influence. Therefore, a generalized non-associated flow, that is $0 \leq \psi \leq \phi$, should be introduced into the numerical method, which has been implemented in our model. 
a

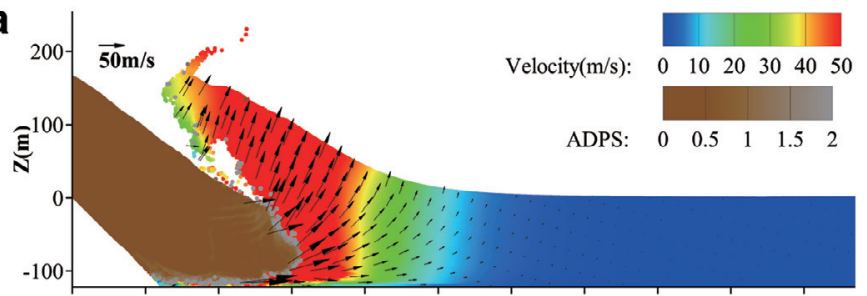

b

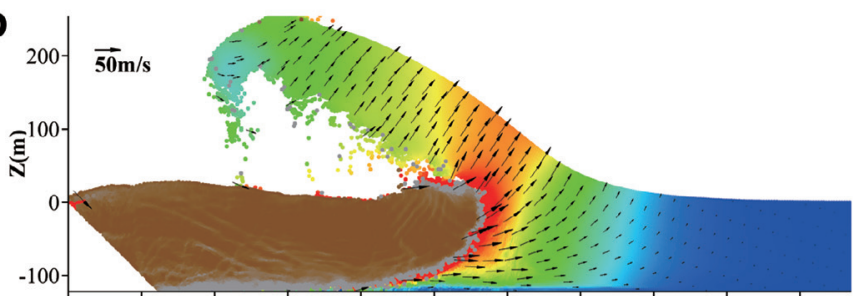

C

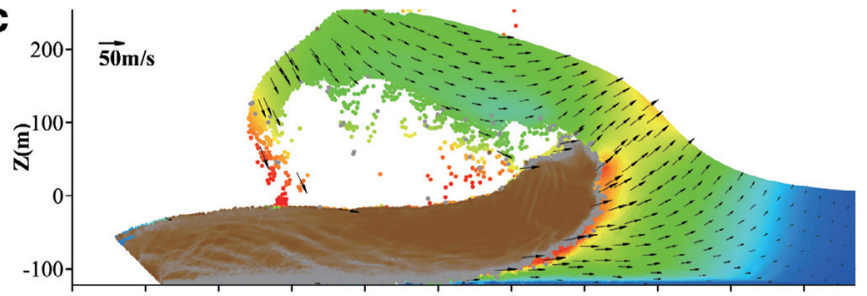

d

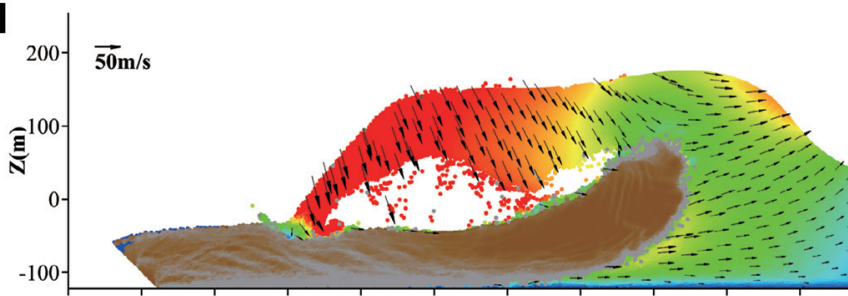

e

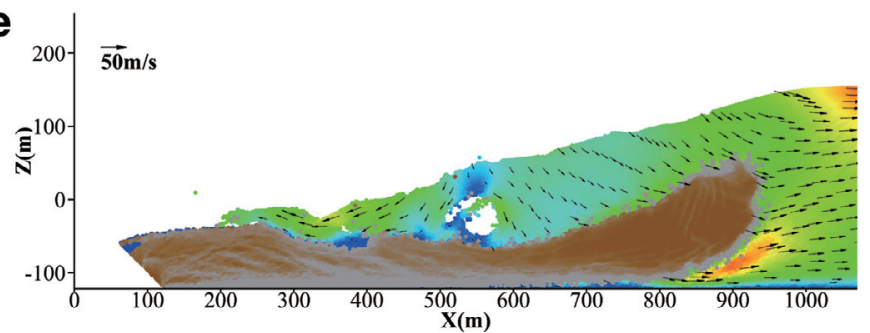

$\mathbf{f}$

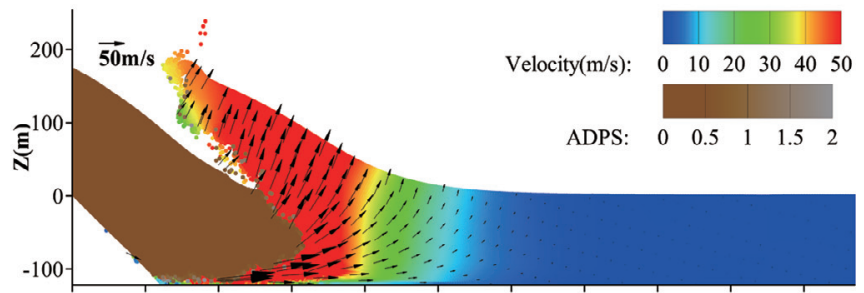

g

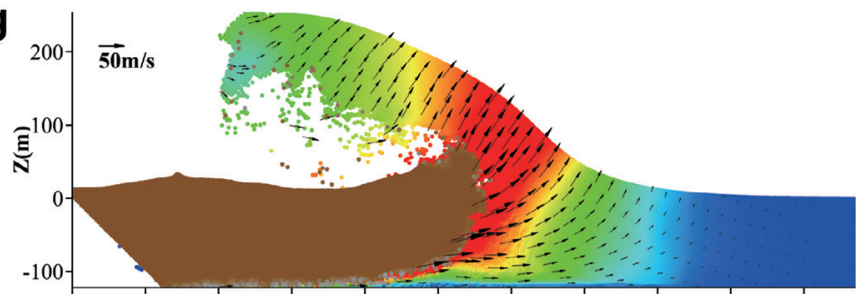

h

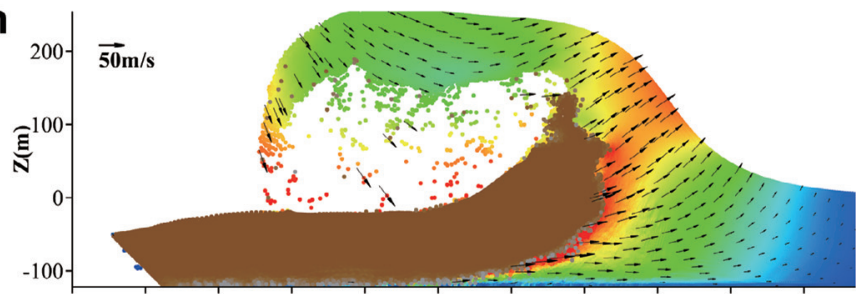

i

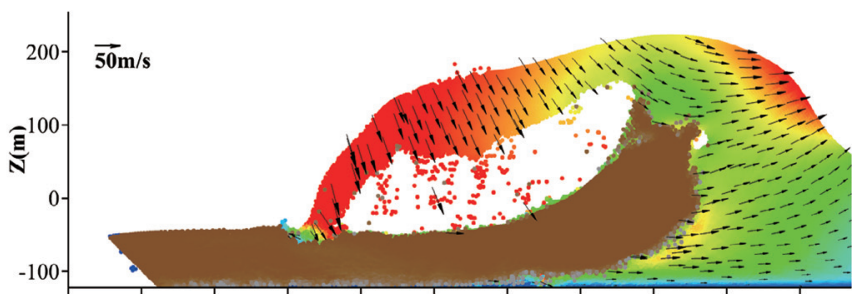

j

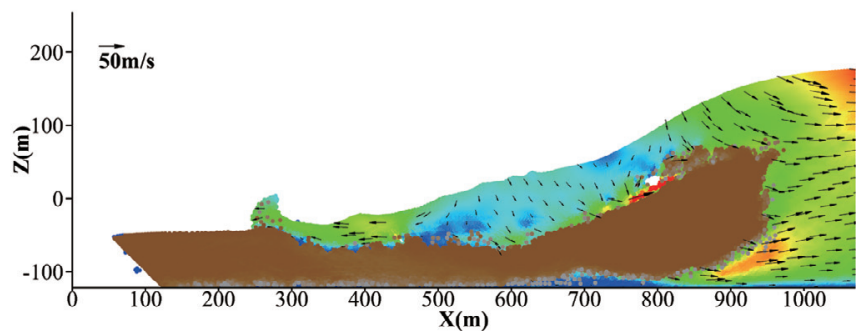

Fig. 9. Simulation result with $\psi=0$ (left) and $\psi=43^{\circ}$ (right). (a) \& (f) $t=4.22 \mathrm{~s}$, (b) \& (g) $t=7.68 \mathrm{~s}$, (c) \& (h) $t=11.14 \mathrm{~s},(\mathrm{~d}) \&(\mathrm{i}) \mathrm{t}=14.6 \mathrm{~s}$ and (e) \& (j) $\mathrm{t}=18.06 \mathrm{~s}$.

In the case of a slow landslide, the simulated results using $\psi=$ 0 and $\psi=0.5 \phi=12^{\circ}$ show little difference between each other (Fig. 8). This will be different in the case of a fast landslide. $\psi=\phi$ (Fig. 9) will make the simulation unreal, unlike $\psi=\phi / 3=14^{\circ}$ (Fig. 7). We can also see that the soil deformation is very different in this two cases $\left(\psi=0\right.$ and $\left.\psi=43^{\circ}\right)$. When dilatancy angle is large, the volume of the slide expands while the plastics zone in the slide is relative small. On the contrary, when dilatancy is ignored, not only the plastics band near the bottom and the watersoil interface developed, but also the inner plastics bands appear. In Fig. 10, we can see quantitatively that the simulations of the non-associated flow rule $\left(\psi=0\right.$ and $\left.\psi=14^{\circ}\right)$ have similar landslide profiles, water elevation and run-up height, which is much different from the simulation of the associated flow rule $\psi=\phi$. However, until now, experiments of landslide-generated impulse waves, such as experimental examples by Viroulet et al., Fritz et al., and the CEMAGREF Institute, ignored the dilatancy angle measure, which makes the validation of the proposed model undetermined for this specific feature.

In conclusion, it is necessary to select the non-associated flow rule for the simulation of the waves generated by landslides and it is also important to choose a reasonable value for the dilatancy angle to achieve the best result. Fortunately, when we need to apply the proposed model in the future, we can determine the dilatancy angle from experiments, or reasonable engineering estimations, because the result is not very sensitive as long as the range is correct.

\section{Conclusions}

The process of landslide-generated impulse waves is simulated with a novel soil-water coupling model. The water is modeled as a 

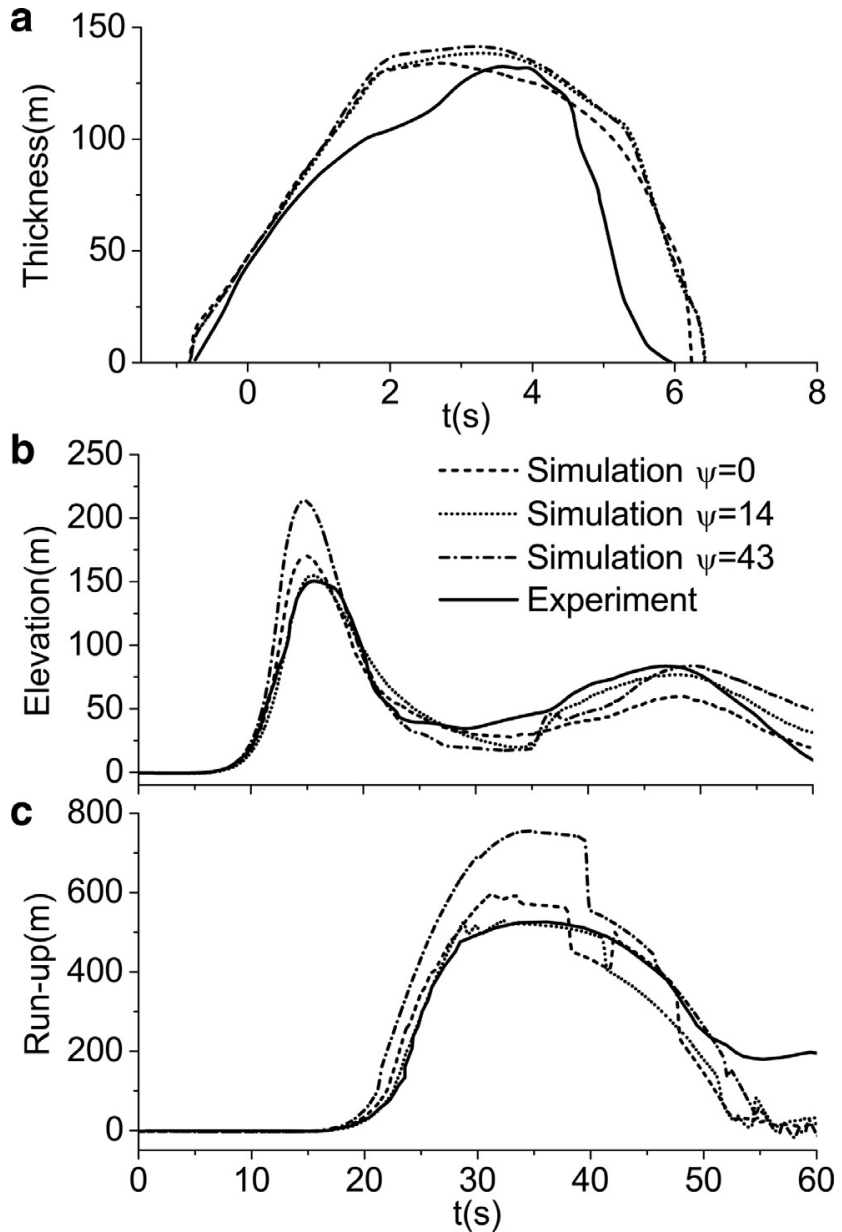

Fig. 10. Comparison of the SPH solution with experimental data when $\psi=0$, $\psi=14^{\circ}$ and $\psi=43^{\circ}$. (a) Granular slide profile scanned with a laser distance sensor orthogonal to ramp at location $x=-67 \mathrm{~m}$ and $\mathrm{z}=67 \mathrm{~m}$. (b) Elevation of the free surface at location $x=885 \mathrm{~m}$. (c) Run-up height on headland ramp at locations $\mathrm{x}=1342 \mathrm{~m}+$ Run-up.

viscous fluid with weak compressibility, while the soil is modeled as an elasto-plastic material. Bilateral interaction between soil and water at the interface is implemented in a simple and direct way. Two experimental examples, waves generated by a slow (Viroulet et al.) and a fast landslide (Fritz et al), were simulated to test the validity of the proposed model. Good agreement between simulation results and experimental data is obtained.

Two significant characteristics can be seen in our model: (1) all parameters in our model have their physical meaning in soil mechanics and can be obtained from normal soil mechanics experiments; and (2) our model can successfully simulate the deformation of the landslide body. The influence of the dilatancy angle on simulating the impulse waves is also discussed. It is necessary to select the non-associated flow rule and to choose a reasonable value range for the dilatancy angle when applying the proposed model.

\section{Acknowledgments}

This study was financially supported by the National Natural Science Foundation of China (No. 11372326, No.11432015) and the National Basic Research Program of China (No. 2014 CB04680202). The author would also like to thank Dr. Wang Xiaoliang for helpful discussion.

\section{References}

Ataie-Ashtiani, B., Shobeyri, G., 2008. Numerical simulation of landslide impulsive waves by incompressible smoothed particle hydrodynamics. Int. J. Numer. Meth Fluids 56 (2), 209-232.

Basu, D., Green, S., Das, K., Janetzke, R., Stamatakos, J., 2010. Numerical simulation of surface waves generated by a subaerial landslide at Lituya Bay, Alaska. J. Offshore Mech. Arct. Eng. 132 (4), 41101.

Bui, H.H., Fukagawa, R., Sako, K., Ohno, S., 2008. Lagrangian meshfree particles method (SPH) for large deformation and failure flows of geomaterial using elastic-plastic soil constitutive model. Int. J. Numer. Anal. Meth. Geomech. 32 (12), 1537-1570.

Capone, T., Panizzo, A., Monaghan, J.J., 2010. SPH modelling of water waves generated by submarine landslides. J. Hydraul. Res. 48 (sup1), 80-84.

Cremonesi, M., Frangi, A., Perego, U., 2011. A Lagrangian finite element approach for the simulation of water-waves induced by landslides. Comput. Struct. 89 (11-12), 1086-1093.

Crespo, A.J.C., Gómez-Gesteira, M., Dalrymple, R.A., 2007. Boundary conditions generated by dynamic particles in SPH methods. Comput. Mater. Continua. 5 (3) 173-184.

Dalrymple, R.A., Knio, O., 2000. SPH modelling of water waves. In: Procedeeings Coastal Dynamics, Lund.

Fritz, H.M., Hager, W.H., Minor, H.E., 2001. Lituya Bay case: rockslide impact and wave run-up. Sci. Tsunami Hazards 19 (1), 3-22.

Fritz, H.M., Hager, W.H., Minor, H.E., 2003. Landslide generated impulse waves, Part 1: Instantaneous flow fields. Exp. Fluids 35 (6), 505-519.

Fritz, H.M., Hager, W.H., Minor, H.E., 2004. Near field characteristics of landslide generated impulse waves. J. Waterw. Port Coast. Ocean Eng. 130 (6), 287-302.

Fritz, H.M., Mohammed, F., Yoo, J., 2009. Lituya Bay landslide impact generated mega-tsunami 50th anniversary. Pure Appl. Geophys. 66 (1-2), 153-175.

Heinrich, P., 1992. Nonlinear water waves generated by submarine and aerial landslides. J. Waterw. Port Coast. Ocean Eng. 118 (3), 249-266.

Heller, V., Spinneken, J., 2013. Improved landslide-tsunami prediction: effects of block model parameters and slide model. J. Geophys. Res. Oceans 118 (3), 1489-1507.

Huang, Y., Hao, L., Xie, P., Xu, Q., 2009. Numerical simulation of large deformation of soil flow based on SPH method. Chinese J. Geotech. Eng. 31 (10), 1520-1524.

Huang, Y., Dai, Z., 2014. Large deformation and failure simulations for geo-disasters using smoothed particle hydrodynamics method. Eng. Geol. 168, 86-97.

Huang, Y., Cheng, H., Dai, Z., Xu, Q., Liu, F., Sawada, K., Moriguchi, S., Yashima, A., 2015. SPH-based numerical simulation of catastrophic debris flows after the 2008 Wenchuan earthquake. Bull. Eng. Geol. Environ. 74 (4), 1137-1151.

Huang, Y., Zhang, W., Dai, Z., Xu, Q., 2013. Numerical simulation of flow processes in liquefied soils using a soil-water-coupled smoothed particle hydrodynamics method. Nat. Hazards 69 (1), 809-827.

Liang, D., He, X., 2014. A comparison of conventional and shear-rate dependent Mohr-Coulomb models for simulating landslides. J. Mt. Sci. 11 (6), 1478-1490.

Liu, G.R., Liu, M.B., 2004. Smoothed Particle Hydrodynamics: a Meshfree Particle Method. World Scientific, Singapore.

Mader, C.L., Gittings, M.L., 2002. Modeling the 1958 Lituya Bay mega-tsunami, II. Sci. Tsunami Hazards 20 (5), 241-250.

Manenti, S., Pierobon, E., Gallati, M., Sibilla, S., D’Alpaos, L., Macchi, E., Todeschini, S., 2015. Vajont Disaster: smoothed particle hydrodynamics modeling of the postevent 2D experiments. J. Hydraul. Eng., 05015007.

Manenti, S., Sibilla, S., Gallati, M., Agate, G., Guandalini, R., 2012. SPH simulation of sediment flushing induced by a rapid water flow. J. Hydraul. Eng. 138 (3), $272-284$.

Mariotti, C., Heinrich, P., 1999. Modelling of submarine landslides of rock and soil. Int. J. Numer. Anal. Meth. Geomech. 23, 335-354.

Monaghan, J.J., Kos, A., Issa, N., 2003. Fluid motion generated by impact. J. Waterw. Port Coast. Ocean Eng. 129 (6), 250-259.

Monaghan, J.J., 2005. Smoothed particle hydrodynamics. Rep. Prog. Phys. 68 (8), 1703-1759.

Monaghan, J.J., Kos, A., 1999. Solitary waves on a Cretan beach. J. Waterw. Port Coast. Ocean Eng. 125, 145-154.

Quecedo, M., Pastor, M., Herreros, M.I., 2004. Numerical modelling of impulse wave generated by fast landslides. Int. J. Numer. Methods Eng. 59, 1633-1656.

Rzadkiewicz, S.A., Mariotti, C., Heinrich, P., 1997. Numerical simulation of submarine landslides and their hydraulic effects. J. Waterw. Port Coast. Ocean Eng. 123 (4) 149-157.

Schwaiger, H.F., Higman, B., 2007. Lagrangian hydrocode simulations of the 1958 Lituya Bay tsunamigenic rockslide. Geochem. Geophys. Geosyst. 8 (7), 007006.

Serrano-Pacheco, A., Murillo, J., García-Navarro, P., 2009. A finite volume method for the simulation of the waves generated by landslides. J. Hydrol. 373 (3-4), 273-289.

Shao, S., Lo, E.Y.M., 2003. Incompressible SPH method for simulating Newtonian and non-Newtonian flows with a free surface. Adv. Water Resour. 26 (7), 787-800.

Shakibaeinia, A., Jin, Y.C., 2011. A mesh-free particle model for simulation of mobile-bed dam break. Adv. Water Resour. 34 (6), 794-798.

Shao, S., 2012. Incompressible smoothed particle hydrodynamics simulation of multifluid flows. Int. J. Numer. Meth. Fluids 69 (11), 1715-1735.

Shi, C.Q. An, Y., Yang, J.X., 2015. A SPH based numerical method of landslide induced impulse wave and its application on Huangtian landslide event. Sci. Sin.-Phys. Mech. Astron. 45, 104706.

Vacondio, R., Mignosa, P., Pagani, S., 2013. 3D SPH numerical simulation of the wave generated by the Vajont rockslide. Adv. Water Resour. 59, 146-156. 
Verlet, L., 1967. Computer experiments on classical fluids. I. Thermodynamical propeties of Lennard-Jones molecules. Phys. Rev. 159, 98-103.

Viroulet, S., Cébron, D., Kimmoun, O., Kharif, C., 2013. Shallow water waves generated by subaerial solid landslides. Geophys. J. Int. 193 (2), 747-762.

Viroulet, S., Sauret, A., Kimmoun, O., Kharif, C., 2013. Granular collapse into water: toward tsunami landslides. J. Vis. 16 (3), 189-191.

Viroulet, S., Sauret, A., Kimmoun, O., 2014. Tsunami generated by a granular collapse down a rough inclined plane. Europhys. Lett. 105, 34004.
Walder, J.S., Watts, P., Sorensen, O.E., Janssen, K., 2003. Tsunamis generated by subaerial mass flows. J. Geophys. Res. 108 (B5), 2236.

Weiss, R., Fritz, H.M., Wünnemann, K., 2009. Hybrid modeling of the mega-tsunami runup in Lituya Bay after half a century. Geophys. Res. Lett. 36 (9), L09602.

Wu, Q., An, Y., Liu, Q.Q., 2015. SPH-based simulations for slope failure considering soil-rock interaction. Procedia Eng. 102, 1842-1849.

Xu, W., 2012. CEL algorithm study of reservoir surge induced by landslide. J. Eng. Geology 20 (3), 350-354. 